\title{
Lesion bacterial communities in American lobsters with diet-induced shell disease
}

\author{
Robert A. Quinn ${ }^{1}$, Anita Metzler ${ }^{2}$, Michael Tlusty ${ }^{2}$, Roxanna M. Smolowitz $^{3}$, \\ Paul Leberg ${ }^{1}$, Andrei Y. Chistoserdov ${ }^{1, *}$ \\ ${ }^{1}$ Department of Biology, University of Louisiana-Lafayette, PO Box 42451, Lafayette, Louisiana 70504, USA \\ ${ }^{2}$ New England Aquarium, Central Wharf, Boston, Massachusetts 02110, USA \\ ${ }^{3}$ Department of Biology and Marine Biology, Roger Williams University, Bristol, Rhode Island 02809, USA
}

\begin{abstract}
In southern New England, USA, shell disease affects the profitability of the American lobster Homarus americanus fishery. In laboratory trials using juvenile lobsters, exclusive feeding of herring Clupea harengus induces shell disease typified initially by small melanized spots that progress into distinct lesions. Amongst a cohabitated, but segregated, cohort of 11 juvenile lobsters fed exclusively herring, bacterial communities colonizing spots and lesions were investigated by denaturing gradient gel electrophoresis of 16S rDNA amplified using 1 group-specific and 2 universal primer sets. The Bacteroidetes and Proteobacteria predominated in both spots and lesions and included members of the orders Flavobacteriales (Bacteriodetes), Rhodobacterales, Rhodospirillales and Rhizobiales (Alphaproteobacteria), Xanthomonadales (Gammaproteobacteria) and unclassified Gammaproteobacteria. Bacterial communities in spot lesions displayed more diversity than communities with larger (older) lesions, indicating that the lesion communities stabilize over time. At least 8 bacterial types persisted as lesions developed from spots. Aquimarina 'homaria', a species commonly cultured from lesions present on wild lobsters with epizootic shell disease, was found ubiquitously in spots and lesions, as was the 'Candidatus Kopriimonas aquarianus', implicating putative roles of these species in diet-induced shell disease of captive lobsters.
\end{abstract}

KEY WORDS: Shell disease - Aquimarina - Denaturing gradient gel electrophoresis - DGGE · Flavobacteria $\cdot$ Herring diet $\cdot$ Homarus americanus

\section{INTRODUCTION}

Shell diseases causing cuticle damage and melanization occur ubiquitously in crustaceans. In the late 1990s, epizootic shell disease (ESD) emerged in the American lobster Homarus americanus H. Milne Edwards, 1837 fishery off the southern coast of New England, USA (Castro \& Angell 2000), where it caused significant financial losses (Hsu \& Smolowitz 2003). The average prevalence of ESD from south of Cape Cod to central Long Island Sound was approximately 20 to $30 \%$ from 1998 to 2005 (Cobb \& Castro 2006). However, prevalence $>70 \%$ has been recorded in ovigerous females in eastern Long Island
Sound in 2002 (Cobb \& Castro 2006). Lobsters that molt out of their shells affected by ESD usually survive (Smolowitz et al. 2005). However, lobsters affected even mildly by ESD are generally unmarketable due to the grotesque appearance of erosions in the dorsal cephalothorax and abdomen that extend laterally in an irregular pattern uncharacteristic of other known forms of shell disease (Smolowitz et al. 2005). Histological analyses of ESD lesions are typified by shallow erosions in the epicuticle and exocuticle, but in severe cases these erosions can penetrate into the uncalcified endocuticle or further into the underlying epithelium causing ulceration (Smolowitz et al. 2005). 
Bacteria, fungi, protistans and nematodes have been observed in ESD lesions (Chistoserdov et al. 2005, Quinn et al. 2009). However, high numbers of bacteria generally occur at lesion edges and within pits in the lesions that develop in the cuticle (Hsu \& Smolowitz 2003, Smolowitz et al. 2005). The culturable bacterial community existing within ESD lesions has been defined using various media (Chistoserdov et al. 2002, 2005). Of the bacteria identified, Pseudoalteromonas gracilis and members of the Flavobacteriaceae were particularly prevalent, with Shewanella spp., Vibrio spp., Pseudoalteromonas spp. and Alteromonas arctica less prevalent (Chistoserdov et al. 2005). Using DNA-based community profiling techniques, Aquimarina 'homaria' (Flavobacteriaceae) and a specific alphaproteobacterium belonging either to the genus Thalassobius or a sister genus ('Marinosulfuromonas') have been found to occur ubiquitously in ESD lesions (Chistoserdov et al. 2009). Culturing of bacteria from lesions of lobsters with impoundment shell disease has predominantly identified Vibrio, Aeromonas, Beneckea and Pseudomonas spp. (Malloy 1978, Stewart 1980, Getchell 1989, Smolowitz et al. 1992). Many of the aforementioned bacteria are known to be chitinoclastic (Chistoserdov et al. 2005). Koch's postulates have not yet been fulfilled for any single bacterial species as the primary cause of any shell lesion type. Thus, the possibility exists that a complex microbial community might become established in and induce erosions as a result of specific environmental and host factors that compromise lobster health, carapace composition or immune competence (Smolowitz et al. 2005, Castro et al. 2006, Tlusty et al. 2007). One such factor that can induce shell disease and mortality in juvenile Homarus americanus is inadequate diet (Tlusty et al. 2008). A diet of herring Clupea harengus has been shown to induce high levels of shell disease and mortality and a mixed diet of crabs, mussels and commercial shrimp feed and diets containing $50 \%$ herring also induce shell disease, although at slightly reduced prevalence (Tlusty et al. 2008).

Here we use the diet-induced shell disease (DISD) method developed by Tlusty et al. (2008) to track the constituents of bacterial communities that become established in spots and lesions induced in juvenile Homarus americanus. To do this, PCR with universaland group-specific 16S rDNA primer sets was used in conjunction with denaturing gradient gel electrophoresis (DGGE) to compare band profiles and to identify bacteria inhabiting spots and lesions of lobsters affected by DISD.

\section{MATERIALS AND METHODS}

\section{Lobster rearing}

Lobsters were reared from eggs at the New England Aquarium Lobster Research and Rearing Facility (Boston, MA). Larvae were fed Spirulina-enriched frozen adult brine shrimp (Artemia spp., San Francisco Bay Brand) and Cyclopeeze (Argent Chemical Laboratories). Upon metamorphosis to Stage IV, individual lobsters were placed into $4.5 \mathrm{~cm}$ diameter containers. From $\sim 1$ yr of age onwards, lobsters were fed a gelatin-based diet containing Progression 3 shrimp aquaculture feed (Salt Creek), krill meal, soy lecithin, various vitamins and minerals, bone meal, kelp meal, Spirulina algae, and frozen Spirulina-enriched adult Artemia.

\section{Induction of shell lesions}

At 3.5 to $4 \mathrm{yr}$ of age (23.5 to $33.2 \mathrm{~mm}$ carapace length, 7.8 to $25 \mathrm{~g}$ body weight), 11 lobsters were housed individually in $13.5 \times 7.2 \times 9$ cm lidded containers that contained side slots for water flow and top circular holes large enough to add feed but prevent escape. The 11 containers were placed in a shallow tank $(193 \times 53 \times 10 \mathrm{~cm})$ employing a semi-closed re-circulating seawater system $(15 \%$ water replacement daily) and maintained for 180 to $245 \mathrm{~d}$; therefore, although physically separated, the animals shared a common water supply. Our experimental design induced a single outbreak of shell disease, so that the sample size is 1 , with a subsample size of 11 lobsters. Lobsters serving as controls were fed a balanced diet as per Tlusty et al. (2008) and never developed DISD even though they were maintained in the same system. The water source and treatment is as described in Tlusty et al. (2008). Over this period, water salinity varied minimally (30.33 to $31.73 \%$ ) and temperatures ranged between 10.6 and $17.5^{\circ} \mathrm{C}$. The diet was made by homogenizing $150 \mathrm{~g}$ frozen herring (Walcan Seafood) and mixing the slurry with $90 \mathrm{ml}$ of hot dissolved Knox gelatin (7.1 g of gelatin in distilled water) to create water soluble blocks of food, which were stored at $-20^{\circ} \mathrm{C}$. Each lobster received a piece of frozen herring homogenate approximately half the size of its last abdominal segment each day, and any uneaten food was removed after $4 \mathrm{~h}$.

Lobsters were observed for shell disease on Day 0 and Day 50 and bi-weekly thereafter until sampled. Because Tlusty et al. (2008) had shown that lobsters succumb to shell disease as severity increases, a 
severity score system was used along with time since onset of disease to ensure lobsters had a sufficient degree of shell disease without a possibility of death. The system was based on the number of carapace locations exhibiting disease spots and/or lesions (lobster carapace was divided into 27 different sections). Using this system 3 lobsters (1-3) were sampled after $180 \mathrm{~d}, 4$ lobsters (4-6 and 9) after $201 \mathrm{~d}$, and 4 lobsters $(7,8,10$ and 11) after 245 d. Lobsters were rinsed in sterile seawater before either regions of normal carapace (6 lobsters) or regions displaying spots or lesions (all 11 lobsters) were scraped using a sterile razor blade. Typically material from all spots ( $\sim 5.5$ per animal) or all lesions ( $\sim 5.7$ per animal) were pooled for each animal. The entire carapace surface was scraped to sample unaffected sections of the carapaces. As less matter was visibly collected from normal carapace and spots compared to lesions, material was suspended in either 50 or $200 \mu$ l buffer (50 mM Tris-HCl pH 8.8, 1 mM EDTA), respectively.

\section{DNA extraction}

Suspended shell matter was made to $1 \mathrm{mg} \mathrm{ml}^{-1}$ egg white lysozyme (Amresco ${ }^{\circledR}$ ) and incubated at $37^{\circ} \mathrm{C}$ for $30 \mathrm{~min}$ before addition of sodium dodecyl sulphate to a $2 \%$ final concentration and $1.25 \mathrm{mg} \mathrm{ml}^{-1}$ Proteinase K (Fisher Bioreagents ${ }^{\circledR}$ ). Following digestion at $50^{\circ} \mathrm{C}$ for $15 \mathrm{~min}$, the lysate was freeze-thawed $\left(-80^{\circ} \mathrm{C}\right.$ and $\left.50^{\circ} \mathrm{C}\right) 3$ times before being mechanically disrupted using $3 \times 0.1 \mathrm{~mm}$ Zirconia/Silica beads in a Mini-Beadbeater ${ }^{\mathrm{TM}}-8$ (BioSpec Products). The pulverized lysate was then extracted with an equal volume of phenol buffered with Tris-HCl, pH7 (SigmaAldrich) followed by an equal volume of chloroform (Fisher-Biotech), and DNA was precipitated at $-80^{\circ} \mathrm{C}$ following addition of $1 / 10$ volume $3 \mathrm{M}$ sodium acetate pH 8.5 and 2.2 volume cold ethanol. Following centrifugation, DNA pellets were washed in $70 \%$ ethanol, dried and resuspended in $200 \mu$ sterile $\mathrm{ddH}_{2} \mathrm{O}$ and stored at $-20^{\circ} \mathrm{C}$.

\section{PCR}

For DGGE analysis, 16S rDNA variable regions V3, V4 and V5 were amplified by PCR using the universal primers 341FM (5'-CCT ACG GGD GGC WGC AG-3') and 907RM (5'-CCG YCW ATT CMT TTG AGT TT-3') modified slightly from sequences described previously (Muyzer 1999). The 5' GCclamp, designed by Muyzer et al. (1993), was at- tached to the $5^{\prime}$ terminus of the $341 \mathrm{FM}$ primer. The resulting primer is designated 341FM-GC. Each PCR $(50 \mu \mathrm{l})$ contained $25 \mu \mathrm{GoTaq}^{\circledR}$ Green Master Mix (Promega), $1.5 \mu \mathrm{M}$ 341FM-GC and $0.5 \mu \mathrm{M}$ 907RM, an additional $1.0 \mathrm{mM} \mathrm{MgCl}_{2}$ and $1.5 \mu \mathrm{l}$ DNA estimated to contain either $\sim 1 \mathrm{ng}$ or $\sim 10 \mathrm{ng}$ DNA from the extractions of melanized spots or lesions, respectively. The touchdown thermal cycling conditions were $95^{\circ} \mathrm{C}$ for $5 \mathrm{~min}, 20$ cycles of $95^{\circ} \mathrm{C}$ for $1 \mathrm{~min}, 65^{\circ} \mathrm{C}$ for $1 \mathrm{~min}$ touchdown $-0.5^{\circ} \mathrm{C}$ per cycle to $55^{\circ} \mathrm{C}$ for $1 \mathrm{~min}, 72^{\circ} \mathrm{C}$ for $3 \mathrm{~min}, 15$ cycles of $95^{\circ} \mathrm{C}$ for $1 \mathrm{~min}$, $55^{\circ} \mathrm{C}$ for $1 \mathrm{~min}$, and $72^{\circ} \mathrm{C}$ for $3 \mathrm{~min}$ followed by $72^{\circ} \mathrm{C}$ for $7 \mathrm{~min}$. To amplify $16 \mathrm{~S}$ rDNA regions V1 and V2 of bacteria, the universal primers $27 \mathrm{~F}$ (5'-AGA GTT TGA TCM TGG CTC AG-3') and 355R (5'-GCT GCC TCC CGT AGG AGT-3') were used. The 5' GCclamp, designed by Muyzer et al. (1993), was attached to the 5 ' terminus of the $27 \mathrm{~F}$ primer. The resulting primer is designated 27F-GC. The PCR was performed as above except using $0.5 \mathrm{mM}$ of each primer and the thermal cycling conditions $95^{\circ} \mathrm{C}$ for $5 \mathrm{~min}, 30$ cycles of $95^{\circ} \mathrm{C}$ for $30 \mathrm{~s}, 59^{\circ} \mathrm{C}$ for $30 \mathrm{~s}$, and $72^{\circ} \mathrm{C}$ for $30 \mathrm{~s}$ followed by $72^{\circ} \mathrm{C}$ for $5 \mathrm{~min}$. Bacteroidetes communities were amplified using primer 341FM-GC in conjunction with the Bacteroidetesspecific primer CFB721R (5'-CTG CCT TCG CAA TCG G-3') modified slightly from a sequence described elsewhere (Weller et al. 2000). Thermal cycling conditions were $95^{\circ} \mathrm{C}$ for $3 \mathrm{~min}$ followed by 30 cycles of $95^{\circ} \mathrm{C}$ for $30 \mathrm{~s}, 57^{\circ} \mathrm{C}$ for $45 \mathrm{~s}$, and $72^{\circ} \mathrm{C}$ for $45 \mathrm{~s}$ followed by $72^{\circ} \mathrm{C}$ for $3 \mathrm{~min}$. PCRs to amplify Aquimarina 'homaria' and an unidentified Bacteroidetes used primers designed to $16 \mathrm{~S}$ rDNA sequences determined for these bacteria, and the primer sequences were unique compared to those of other bacteria found associated with ESD lesions or to any sequences deposited in GenBank or the Ribosomal Database Project (RDP) database. The A. 'homaria' PCR primers were AhomF (5'-CAG TAT TAC GTG TAA TAC T-3') and AhomR (5'-TCA ATG GCA ATT TTC CG-3') and the unidentified Bacteroidetes PCR primers were AcompF (5'-CCC ACC ACG TGT GGT GGG-3') and AcompR (5'-AAT ATA ACT CAA GAC AAC-3'). Thermal cycling conditions were $95^{\circ} \mathrm{C}$ for $3 \mathrm{~min}, 30$ cycles of $95^{\circ} \mathrm{C}$ for $30 \mathrm{~s}, 48.5^{\circ} \mathrm{C}$ for $30 \mathrm{~s}$ for A. 'homaria' or $57^{\circ} \mathrm{C}$ for $30 \mathrm{~s}$ for Bacteroidetes, and $72^{\circ} \mathrm{C}$ for $30 \mathrm{~s}$ followed by $72^{\circ} \mathrm{C}$ for $3 \mathrm{~min}$.

\section{DGGE and band processing}

Gel electrophoresis of PCR products employed a polyacrylamide-based DGGE system (CBS Scientific) 
and $1 \times$ Tris-acetate EDTA buffer, pH 7.8 (FisherBiotech $)$ at $60^{\circ} \mathrm{C}$. All DGGE gels $(20 \times 17.6 \mathrm{~cm}, 1.5 \mathrm{~mm}$ thick) were prepared using $6 \%$ polyacrylamide and concentration gradients of $100 \%$ denaturing solution ( $7 \mathrm{M}$ urea and $40 \%$ formamide). Gradients of 20 to $80 \%$ were employed in gels to resolve $341 \mathrm{~F}+907 \mathrm{R}$ PCR products, 20 to $65 \%$ to resolve $27 \mathrm{~F}+355 \mathrm{R}$ PCR products and 35 to $60 \%$ to resolve $341 \mathrm{~F}+\mathrm{CFB} 721 \mathrm{R}$ PCR products. Gels were subjected to electrophoresis at $80 \mathrm{~V}$ at $60^{\circ} \mathrm{C}$ for $14 \mathrm{~h}$, stained with $0.1 \mathrm{mg} \mathrm{ml}^{-1}$ ethidium bromide for $20 \mathrm{~min}$ and banding patterns were visualized using a UV transilluminator. Bands of interest were excised using a scalpel blade, placed into microcentrifuge tubes containing $0.2 \mathrm{~g}$ sterile $2 \mathrm{~mm}$ glass beads (Biospec Products) and $500 \mu \mathrm{l}$ $\mathrm{ddH}_{2} \mathrm{O}$ and pulverized at high speed for 3 min using a Mini Beadbeater ${ }^{\mathrm{TM}}$ (Biospec Products) before being stored at $4^{\circ} \mathrm{C}$ overnight for DNA extraction.

\section{DNA sequencing}

Aliquots $(1 \mu \mathrm{l})$ of excised bands pulverized in $\mathrm{ddH}_{2} \mathrm{O}$ were reamplified by PCR using the same reverse primer in conjunction with a forward primer of the same sequence except for the absence of the 5'GC-clamp. These PCRs $(50 \mu \mathrm{l})$ contained $25 \mu \mathrm{l}$ GoTaq ${ }^{\circledR}$ Green Master Mix, $0.5 \mu \mathrm{M}$ each primer and $1.5 \mu \mathrm{l}$ DNA and used the thermal cycling conditions described earlier. PCR products were purified using the Wizard ${ }^{\circledR}$ SV PCR Clean-Up System (Promega) and sequenced using one of the aforementioned forward primers and a BigDye ${ }^{\circledR}$ terminator V3.1 cycle sequencing kit. Nucleotide sequences were generated using a 3130xl Genetic Analyzer (Applied Biosystems). BLASTn (Altschul et al. 1997) was used for nucleotide sequence searches of GenBank and the RDP database (http://rdp.cme.msu.edu) to assign phylogenies. Bacterial 16S rDNA sequences were deposited in GenBank (Accession nos. JF297188JF297220 and JF304026), analyzed using Lasergene 5.3 (DNA* ${ }^{*}$ Star) and examined for possible chimeras using the RDP release 8.1 CHIMERA_CHECK program (rdp.cme.msu.edu).

\section{Statistical analysis of community profiles}

Jaccard's similarity index was used to quantify similarities of DGGE profiles of the microbial community identified among the melanized spots and lesions examined (Jaccard 1908). The index measures similarity based on the number of DGGE bands shared between 2 samples divided by the number of bands identified as unique in the 2 samples (Real \& Vargas 1996). Gel images were digitized and TotalLab TL100 version 2008.01 1D gel analysis (TotalLab) was used to identify shared and unique bands.

Because band similarities of 1 sample were determined against several other samples, a randomization approach was used to evaluate their statistical significance compared to averaged index values determined for either spot samples or lesion samples (Manly 1991).

Individual bands from the lesion and spot samples were pooled into a single sample (this is comparable to assuming there is no difference between the samples). Individuals were then randomly reassigned to 2 samples, of the same sizes as the original spot and lesion samples. The average similarity index was then calculated for these 2 new sets of randomized samples, and the difference between the average similarity was obtained. Procedures in Statistical Analysis System (SAS 2008) for randomizing data sets were used to generate these differences in average index values for 10000 data permutations. These 10000 differences between similarity indices represent the variation in differences between index values that would be expected if there was no difference in the community similarities of the lesson and spot samples. If the difference between average similarity index values observed from our original samples was $>95 \%$ of values obtained through randomization, we can conclude that the observed differences in community similarities were statistically significant (Manly 1991).

Procedures in SAS (2008) for randomizing data sets were used to generate index values for difference distributions for 10000 data permutations.

\section{Histology}

Tissue pieces surrounding individual spots were sampled from 2 lobsters and processed for histology. Individual lesions were sampled from 6 lobsters for histology. These individuals were separate from those sampled for DNA extraction to ensure their morphology was not compromised. The carapace was removed by inserting a scalpel and making a circular cut at distance of $\sim 3 \mathrm{~mm}$ away from a lesion or a spot. The scalpel penetrated through the shell into the hemocoel to cut out approximately 2 to $3 \mathrm{~mm}$ thick slices perpendicular to the surface of the lesion. The resulting shell slices also contained the attached underlying epithelium and connective tissues. Tis- 
sues fixed in $10 \%$ formalin in seawater were decalcified using an EDTA solution $\mathrm{pH}$ 8.0, processed into paraffin, $5 \mu \mathrm{m}$ sections were stained using hematoxylin and eosin (Howard et al. 2004) and lesion pathology observed was described using terminology defined by Smolowitz et al. (2002).

\section{RESULTS}

\section{Shell disease development}

Among the 11 lobsters fed exclusively on herring, the times at which shell disease developed varied from 48 to $201 \mathrm{~d}$ (mean $\pm \mathrm{SD}=90.1 \pm 51.9 \mathrm{~d}$ ). Lobsters initially presented melanized spots $<1 \mathrm{~mm}$ diameter with no conspicuous signs of shell erosions, and these generally developed over time into larger, more advanced melanized lesions in which the shell had eroded (Fig. 1). Lesions most often developed on the chelipeds, uropods, and carapace. While most spots appeared as uniform circles, lesions on the cutting and crushing regions of the cheliped were often elongated along the length of the claw. Over the duration of the trial the general health of lobsters declined as evidenced by them losing chelipeds and becoming moribund.

\section{Histopathology}

Histology on single lesions from 6 lobsters showed severe erosions that mostly extended through the

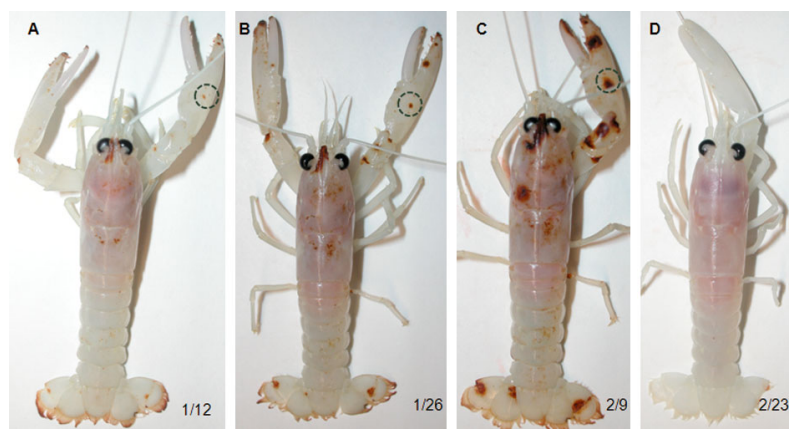

Fig. 1. Homarus americanus. Photographs of a single individual lobster showing the progression of diet-induced shell disease over a $42 \mathrm{~d}$ period. Date codes $(\mathrm{mo} / \mathrm{d})$ for photographs taken in 2009 are shown. Development of a claw spot (dashed circle) into a lesion prior to molting: the spot has (A) just become melanized, (B) progressed to become an early lesion, (C) become a clearly evident lesion and (D) disappeared along with all shell lesions that have been lost following molting

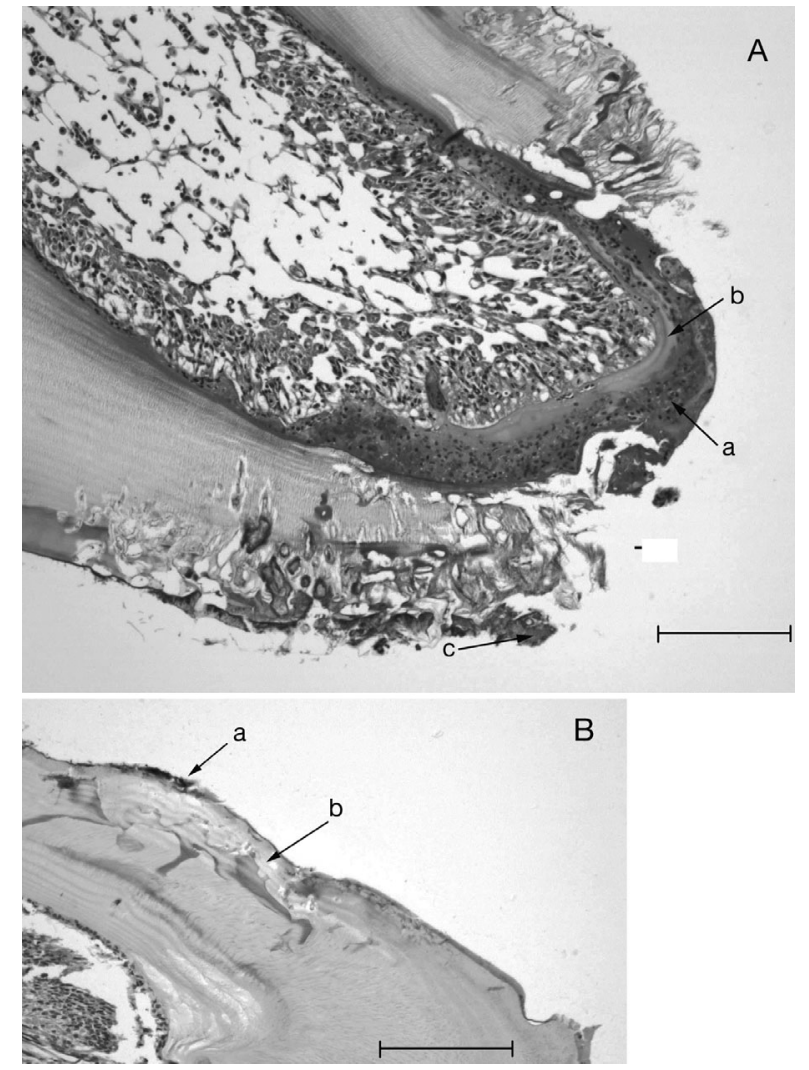

Fig. 2. Homarus americanus. Hematoxylin and eosin stained histological sections of a lesion and a spot on the carapace of a diet-induced shell disease-affected lobster. (A) Lesion characterized by loss of normal carapace cuticle as well as (a) a thickened, melanized pseudo-membrane underlain by (b) a new carapace layer being produced by the cuticular epithelium and (c) colonies of bacteria on eroded cuticle surfaces. (B) Spot showing colonies of bacteria on deformed cuticle as well as (a) exocuticle degeneration and melanization and (b) outer lamellae of the calcified endocuticle. Scale bars $=250 \mu \mathrm{m}$

uncalcified endocuticle but did not penetrate through the epithelium (Fig. 2). They also displayed a thick surface pseudo-membrane and an underlying new cuticle layer formed by the cuticular epithelium. All pseudo-membrane surfaces and adjacent degenerating carapace regions were melanized. Mats of bacteria occurred on some lesion surfaces (Fig. 2A) and small unidentified protozoans often occurred in conjunction with bacteria on surfaces of deep erosions where the cuticle had degenerated. The single spots examined from 2 lobsters were melanized to varying degrees, one at the epicuticle and superficial exocuticle surfaces and the other at deeper areas of the degenerated exocuticle (Fig. 2B). Bacterial mats, individual bacteria and some small protozoans were noted in affected areas of the spots. 


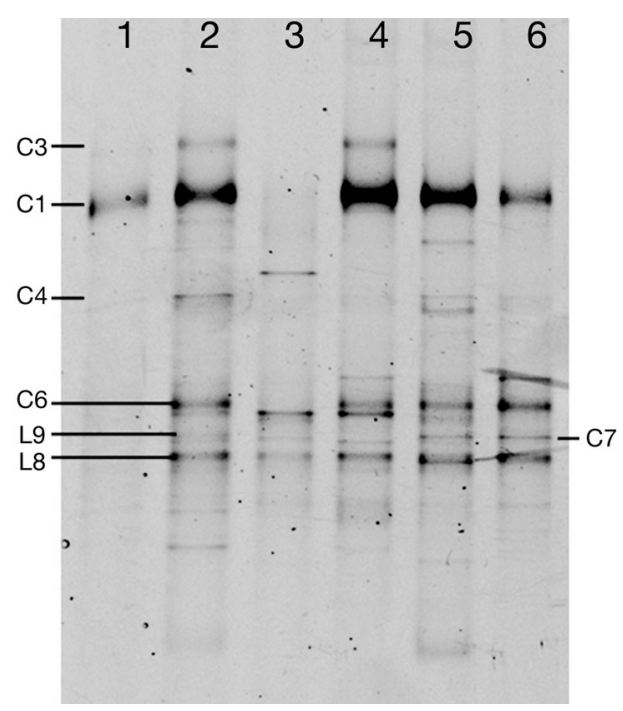

Fig. 3. Denaturing gradient gel electrophoresis showing 16S rDNA bands amplified from lesion bacterial communities using the universal PCR primer set 341FM+907RM. Lane numbers 1 to 6 identify individual lobsters Homarus americanus. ' $\mathrm{C}$ ' bands were amplified from both spots and lesions and ' $\mathrm{L}$ ' bands were amplified only from lesions as described in Tables 1 \& 2, respectively

\section{Primer bias}

Due to known amplification biases of the universal primers (Hong et al. 2009), 2 universal primer sets were tested. When applied to lesions, the 341FM+
907RM primer set amplified both Bacteroidetes and Proteobacteria, whereas the $27 \mathrm{~F}+355 \mathrm{R}$ primer set appeared to favor Proteobacteria (Figs. $3 \& 4$ ). For example, with the lesion from Lobster 5, the 341FM+ 907RM primer set clearly amplified at least 4 different species of Bacteroidetes, whereas the $27 \mathrm{~F}+355 \mathrm{R}$ primer set amplified only 1 . In contrast, with the lesion from Lobster 2 where the $341 \mathrm{FM}+907 \mathrm{RM}$ primer set amplified 7 Proteobacteria species, the $27 \mathrm{~F}+355 \mathrm{R}$ primer set amplified a much higher diversity (up to 19 bands) of Proteobacteria. Both primer sets were thus used across all lesion and spot samples to ensure more complete coverage of all major bacterial lineages, and a second Bacteroidetes-specific primer set was used to ensure good resolution of this group due to the bias of the $27 \mathrm{~F}+355 \mathrm{R}$ primer set.

\section{DGGE analysis of healthy carapace and melanized disease spots}

No PCR products were amplified from DNA extracted from healthy carapace scrapings using either the Bacteroidetes group-specific or the 2 universal primer sets, indicating the presence of few if any bacteria. In disease spots from juvenile lobsters with DISD, 16S rDNA PCR in conjunction with DGGE and band sequence analysis identified bacteria from the Bacteroidetes and Proteobacteria phyla and 1 species of Actinobacteria. The 341FM+907RM
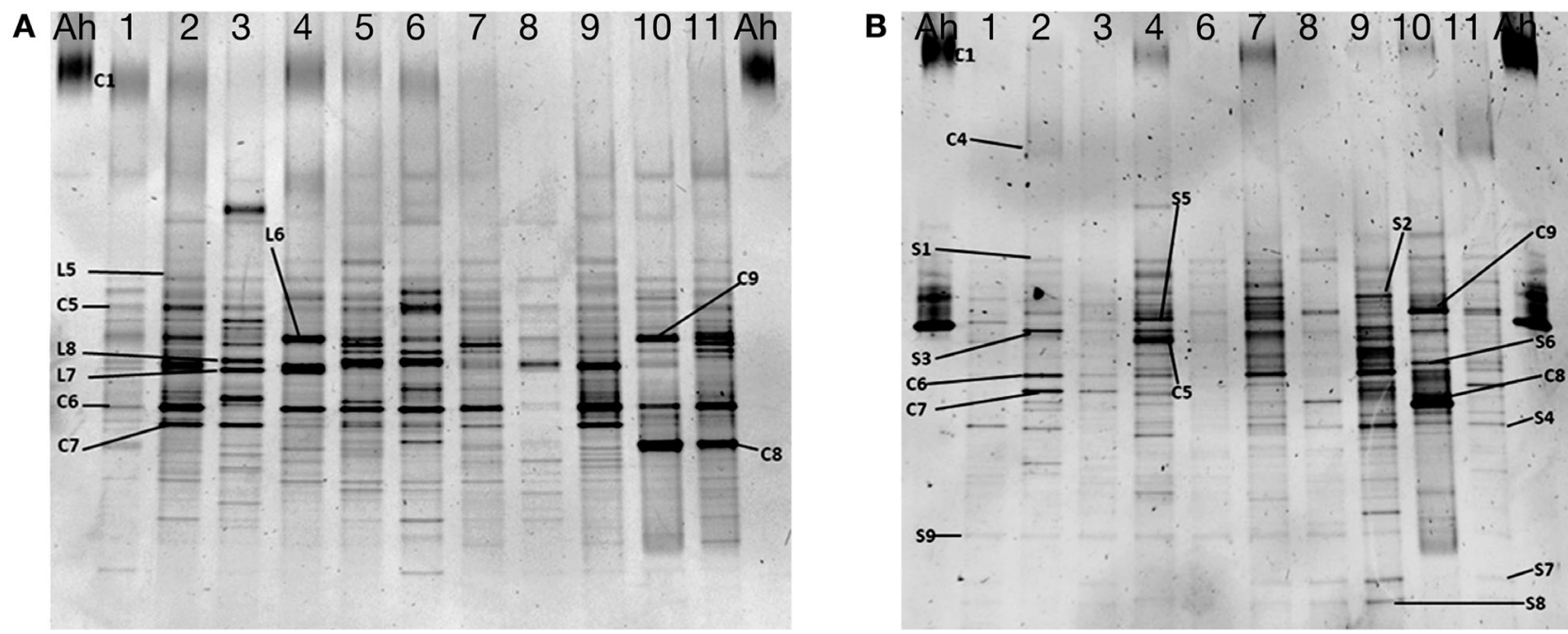

Fig. 4. Denaturing gradient gel electrophoresis showing 16S rDNA bands amplified from (A) lesion and (B) spot bacterial communities using the universal primer set $27 \mathrm{~F}+355 \mathrm{R}$. Lane numbers 1 to 11 identify individual lobsters Homarus americanus. ' $\mathrm{C}$ ' and ' $\mathrm{L}$ ' bands are labeled as in Fig. 3, and ' $\mathrm{S}$ ' bands were amplified exclusively from spot bacterial communities as described in Table 3. Lane Ah includes reference bands of (A) Aquimarina 'homaria' I32.4, and (B) A. 'homaria' I32.4 and

'Thalassobius' sp. I31.1 


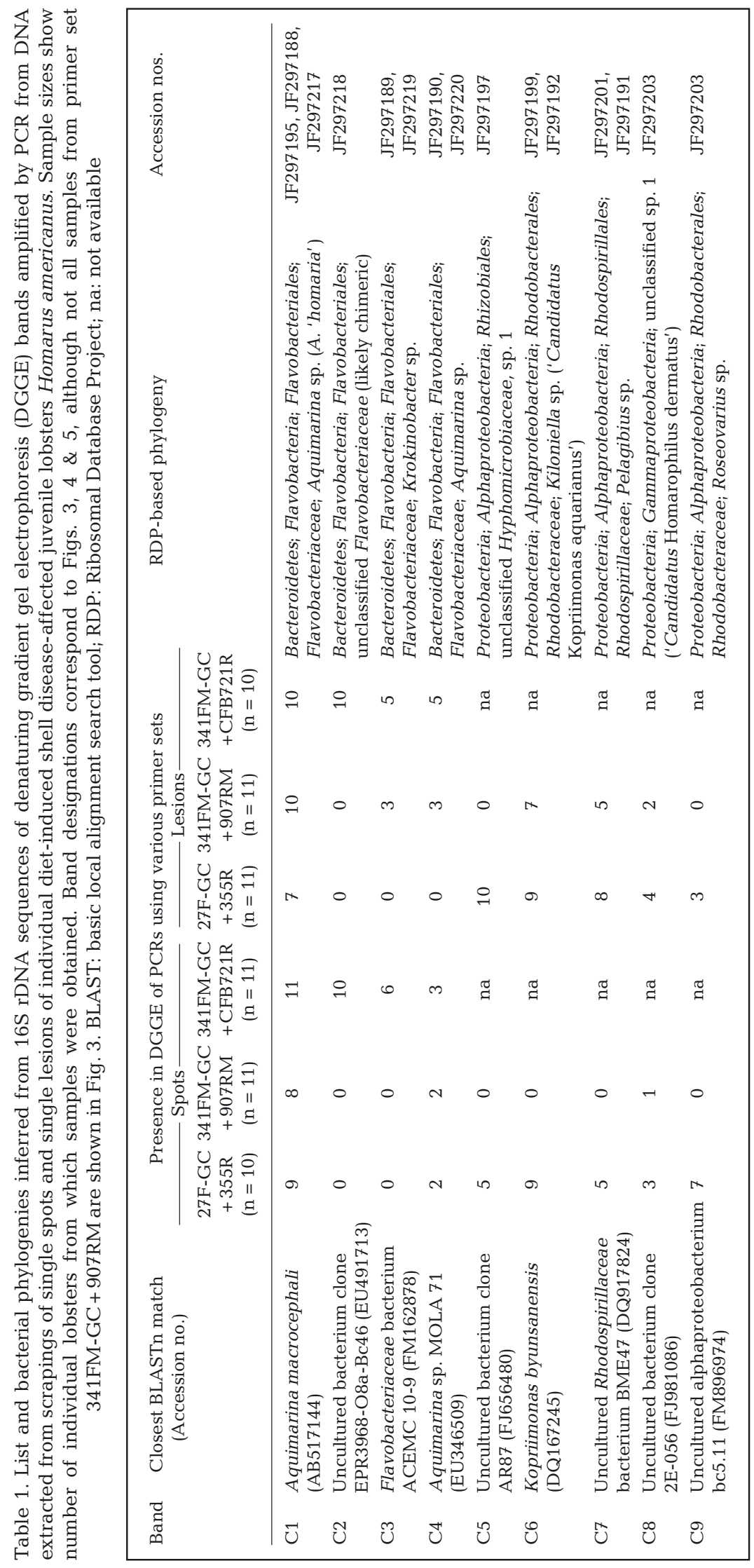

PCR primer set amplified only Aquimarina 'homaria', another Aquimarina sp. and an unidentified gammaproteobacterium, which could not be assigned to existing orders of Gammaproteobacteria ('Candidatus Homarophilus dermatus') (Table 1). Among melanized spots from 10 of the 11 lobsters in which 16S rDNA was amplified successfully with the $27 \mathrm{~F}+355 \mathrm{R}$ PCR primer set, a high diversity of bacteria predominating in Proteobacteria was amplified. A DNA band identified as Aquimarina 'homaria' was also amplified from 9 of the 10 spots. DNA bands were amplified in high prevalence from Alphaproteobacteria, including a Kilionella sp., 2 unclassified Rhodobacteraceae (sp. 2 and 3), a Ruegeria sp., a Hyphomicrobium sp. and a Roseovarius sp. As the 3 putative unclassified Rhodobacteraceae species (sp. 1-3) share only 93 to $95 \% 16 \mathrm{~S}$ rDNA sequence identity with characterized Rhodobacteraceae sp. and each other, it is possible they belong to different genera. Less prevalent Alphaproteobacteria in multiple spots included Sulfitobacter sp., Ruegeria sp. and a Roseovarius sp. (Table 2). Gammaproteobacterial members associated with melanized spots included 2 Lysobacter spp. and the 'Candidatus Homarophilus dermatus', although they were detected less frequently (Table 2). Propionibacterium acnes was amplified from melanized spots from all 10 lobsters.

When applied to DNA extracted from melanized spots, the Bacteroidetes-specific PCR primer set revealed greater flavobacterial diversity than the 341FM+907R primer set, with up to 14 DNA products amplified (Fig. 5, Lobster 7) compared to up to 3 low-yield DNA products per spot, respectively (data not shown). Band C1 (Aquimarina 'homaria') was amplified from spots of 9 of 10 lobsters (Fig. 4), although only in low yields from Lobster 2. A. 'homaria' 16S rDNA sequence identity was con- 
Table 2. List and bacterial phylogenies inferred from 16S rDNA sequences of denaturing gradient gel electrophoresis (DGGE) bands amplified by PCR from DNA extracted from scrapings of single lesions of individual diet-induced shell disease-affected lobsters Homarus americanus. Sample sizes show number of individual lobsters from which samples were obtained. Band designations correspond to Figs. 3, 4 \& 5. BLAST: basic local alignment search tool; RDP: Ribosomal Database Project

\begin{tabular}{|c|c|c|c|c|c|c|}
\hline \multirow[t]{2}{*}{ Band } & \multirow[t]{2}{*}{$\begin{array}{l}\text { Closest BLASTn match } \\
\text { (Accession no.) }\end{array}$} & \multicolumn{3}{|c|}{$\begin{array}{c}\text { Presence in DGGE of } \\
\text { PCRs using various primer sets }\end{array}$} & \multirow[t]{2}{*}{ RDP-based phylogeny } & \multirow[t]{2}{*}{$\begin{array}{l}\text { Accession } \\
\text { no. }\end{array}$} \\
\hline & & $\begin{array}{l}27 \mathrm{~F}-\mathrm{GC}+ \\
55 \mathrm{R}(\mathrm{n}=11)\end{array}$ & $\begin{array}{l}\text { 341FM-GC+ } \\
907 \mathrm{RM}(\mathrm{n}=11)\end{array}$ & $\begin{array}{c}\text { 341FM-GC }+ \\
\text { CFB721R }(\mathrm{n}=10)\end{array}$ & & \\
\hline L1 & $\begin{array}{l}\text { Marine bacterium MSC5 } \\
\text { (EU753120) }\end{array}$ & 0 & 0 & 6 & $\begin{array}{l}\text { Bacteroidetes; Flavobacteria; } \\
\text { Flavobacteriales; Flavobacteriaceae; } \\
\text { Maribacter sp. } 1\end{array}$ & JF297213 \\
\hline L2 & $\begin{array}{l}\text { Maribacter sp. MOLA } 57 \\
\text { (AM990832) }\end{array}$ & 0 & 0 & 2 & $\begin{array}{l}\text { Bacteroidetes; Flavobacteria; } \\
\text { Flavobacteriales; Flavobacteriaceae; } \\
\text { Maribacter sp. } 2\end{array}$ & JF297214 \\
\hline L3 & $\begin{array}{l}\text { Flexibacter aurantiacus subsp. } \\
\text { Copepodarum' (AB078044) }\end{array}$ & 0 & 0 & 3 & $\begin{array}{l}\text { Bacteroidetes; Flavobacteria; } \\
\text { Flavobacteriales; Flavobacteriaceae; } \\
\text { Tenacibaculum sp. } 1\end{array}$ & $\begin{array}{l}\text { JF297215 } \\
\text { JF297216 }\end{array}$ \\
\hline L4 & $\begin{array}{l}\text { Tenacibaculum soleae type } \\
\text { strain LL04 (AM746476) }\end{array}$ & 0 & 0 & 2 & $\begin{array}{l}\text { Bacteroidetes; Flavobacteria; } \\
\text { Flavobacteriales; Flavobacteriaceae; } \\
\text { Tenacibaculum sp. } 2\end{array}$ & \\
\hline L5 & $\begin{array}{l}\text { Uncultured Rhodobacterales } \\
\text { bacterium (EF215733) }\end{array}$ & 11 & 0 & na & $\begin{array}{l}\text { Proteobacteria; Alphaproteobacteria; } \\
\text { Rhodobacterales; unidentified } \\
\text { Rhodobacteraceae sp. } 1\end{array}$ & JF297196 \\
\hline L6 & $\begin{array}{l}\text { Uncultured bacterium clone: } \\
\text { IndB1-38 (AB099999) }\end{array}$ & 10 & 0 & na & $\begin{array}{l}\text { Proteobacteria; Alphaproteobacteria; } \\
\text { Rhizobiales; unclassified } \\
\text { Hyphomicrobiaceae sp. } 2\end{array}$ & JF297198 \\
\hline L7 & $\begin{array}{l}\text { Uncultured marine bacterium } \\
\text { clone 16_01_04D05 (FR683345) }\end{array}$ & ) & 0 & na & $\begin{array}{l}\text { Proteobacteria; Alphaproteobacteria; } \\
\text { Rhodospirillales; Rhodospirillaceae; } \\
\text { Octadecabacter sp. }\end{array}$ & JF297200 \\
\hline L8 & $\begin{array}{l}\text { Marine alphaproteobacterium } \\
\text { JP66.1 (AY007677) }\end{array}$ & 8 & 7 & na & $\begin{array}{l}\text { Proteobacteria; Alphaproteobacteria; } \\
\text { Rhizobiales; Phyllobacteriaceae; } \\
\text { Hoflea sp. }\end{array}$ & JF297204 \\
\hline L9 & $\begin{array}{l}\text { Sulfitobacter sp. NF4-11 } \\
\text { (FJ196047) }\end{array}$ & 0 & 5 & na & $\begin{array}{l}\text { Proteobacteria; Alphaproteobacteria; } \\
\text { Rhodobacterales; Rhodobacteraceae; } \\
\text { Thalassobius sp. }\end{array}$ & JF297194 \\
\hline
\end{tabular}
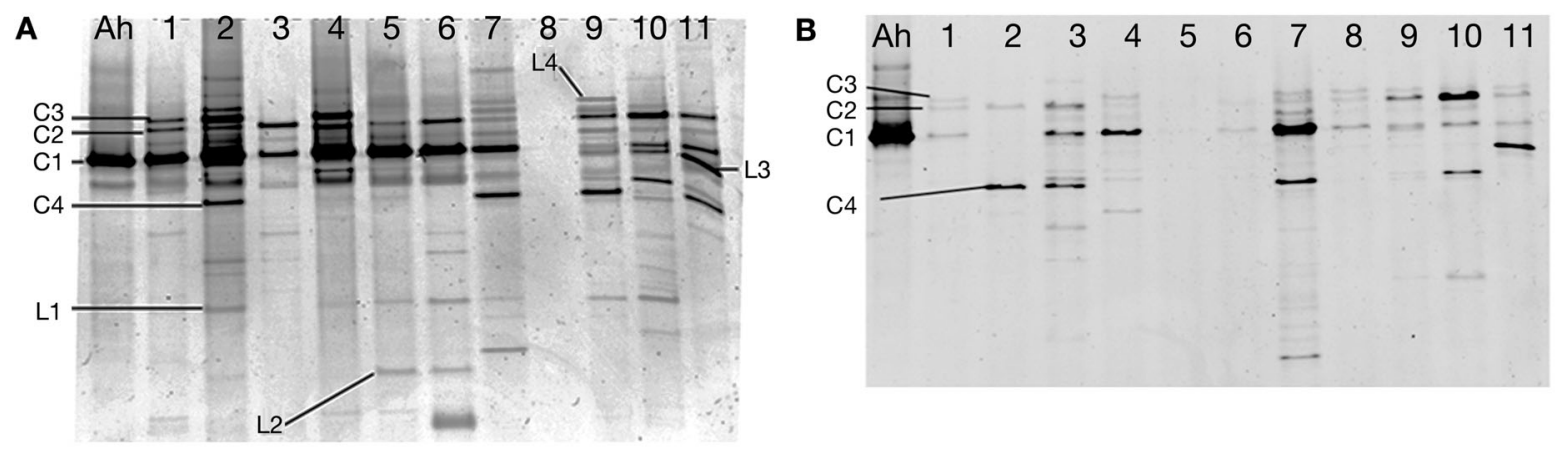

Fig. 5. Denaturing gradient gel electrophoresis showing 16S rDNA bands amplified from Bacteroidetes sp. present in (A) lesion and (B) spot bacterial communities. Lane numbers 1 to 11 identify individual lobsters Homarus americanus and Lane Ah is Aquimarina 'homaria' I32.4 reference DNA. Bands are labeled ' $\mathrm{C}$ ', 'L' and 'S' as in Figs. 3 \& 4 and as described in Tables 1,2 \& 3

firmed following re-amplification. An unclassified Flavobacteriaceae sp. (Band C2) was amplified from 10 of 11 spots (Fig. 5). Other Bacteroidetes identified relatively frequently included the Krokinobacter sp., an unclassified Aquimarina sp., and various other Flavobacteriaceae (Table 2).

\section{DGGE and PCR analyses of bacterial communities from disease lesions}

In lesions of juvenile lobsters with DISD, 16S rDNA PCR in conjunction with DGGE and band sequence analysis identified bacteria from the Bacteroidetes 
and Proteobacteria phyla. The Bacteroidetes were exclusively from the Flavobacteriaceae, whereas Proteobacteria encompassed several families of Alpha- and Gammaproteobacteria.

As the 11 lobsters were held communally within a shallow tank but segregated as individuals within interconnected cubicles, bacterial communities that established in lesions of different lobsters were expected to be similar. Therefore, particular attention was paid to identifying the nature of bacteria that established commonly across the lobsters. Both universal primer sets amplified the Band $\mathrm{C} 1$ in a high number of lesions (Fig. 3, Table 1). Analysis of the 16S rDNA sequence of Band C1 from all 3 primer sets showed it to be identical to that of Aquimarina 'homaria' cultured from ESD lesions of wild lobsters (Chistoserdov et al. 2005). Both universal PCR primer sets also amplified and indicated a common presence of a Pelagibius sp., a Kiloniella sp. (Table 1) and a Hoflea sp. (Table 2). The $27 \mathrm{~F}+355 \mathrm{R}$ primer set also identified the common presence of an unclassified Rhodobacteraceae sp. (sp. 1), 2 different unclassified Hyphomicrobiaceae sp., a Kiloniella sp., an Octadecabacter sp., a Hoflea sp., a Pelagibius sp., other Rhodobacteraceae and 'Candidatus Homarophilus dermatus' (Tables $1 \& 2$ ). In addition, the 341FM+ 907RM primer set identified the common presence of a Thalassobius sp. that the $27 \mathrm{~F}+355 \mathrm{R}$ primers did not reveal (Table 1). Other bacteria types were detected but only in lesions of 1 of the 11 lobsters, and as such have not been described as they are unlikely candidates for being involved in shell disease.

During the experiment, DNA from 1 of the 11 lesions degraded (Lobster 8, Fig. 5) and was therefore not amplifiable with the Bacteroidetes primer set. However, of the remaining 10 lesions, Aquimarina 'homaria' DNA was amplified from all lobsters (Fig. 5). Band C2, belonging to the same uncultured and unclassified Flavobacteriaceae sp., was also amplified from all 10 lesions (Fig. 5). Interestingly, this sequence was not amplified using either of the 2 universal primer sets. The Bacteroidetes-specific PCR primer set also amplified species detected by the other tests including the Krokinobacter sp., 2 unidentified Maribacter spp., 2 Tenacibaculum spp. and another Aquimarina sp. (Tables 1 \& 2).

\section{Comparison of bacterial communities from spots and lesions}

Using the $27 \mathrm{~F}+355 \mathrm{R}$ and $341 \mathrm{FM}+\mathrm{CFB} 721 \mathrm{R} P C R$ primer sets, direct comparsions between bacterial
16S rDNA sequences amplified from spots with those amplified from lesions were possible. The Flavobacteriaceae and Alpha- and Gammaproteobacteria community profiles of spots and lesions were similar overall even though different species were often identified. This similarity may reflect their cohabitation in the same tank water. In both spots and lesions, 8 species were found consistently (Band $\mathrm{C} 2$ is a chimera), 9 species were unique to spots and 9 species were unique to lesions (Tables $1,2 \& 3$ ). Of the 8 common species, only 2, Aquimarina 'homaria' and the Kiloniella sp., were identified in spots or lesions from 9 of the lobsters (Table 1).

Comparisons of the bacteria existing in each spot and each lesion of each individual lobster revealed that community profiles were similar for some, but dissimilar for others. For example, 2 DNA products with identical sequences were amplified in abundance from the spot and the lesions sampled from Lobster 10. In contrast, with Lobster 9, a diverse range of DNA products were amplified from the spot while only 3 DNA products were amplified from the lesion (Fig. 4). Similar phenomena occurred in Bacteroidetes community profiles. For example, DNA band profiles between spots and lesions were similar from Lobsters 1 and 7 but vastly different from Lobsters 2 and 9 (Fig. 5).

Differences in Jaccard similarity indices determined for the 11 spots $($ mean $=0.385)$ and the 11 lesions (mean $=0.459$ ) sampled from the 11 lobsters indicated that spots shared fewer common 16S rDNA products than did lesions and, thus, possessed higher bacterial diversity. Based on analyses of a 10000 randomized data sets, the magnitude of the difference in Jaccard similarity indices (0.074) between spots and lesions was significant $(\mathrm{p}=0.0022)$.

\section{Detection of specific bacteria in lesions}

As each of the 2 universal primer sets amplified Aquimarina 'homaria' and as the $341 \mathrm{FM}+\mathrm{CFB721R}$ primer set amplified the unclassified Flavobacteriaceae sp. in all spot and lesion samples, specific PCR primer sets were designed to confirm the high prevalence of these bacteria. Additional data on $A$. 'homaria' was also obtained. Using the PCR specific for A. 'homaria', a 16S rDNA product was amplified from all 11 spots and all 11 lesions sampled from the 11 lobsters as well as from healthy carapace scrapings from 2 of 6 control lobsters. In contrast, using the PCR specific for the unclassified Flavobacteriaceae sp. sequence (Band $\mathrm{C} 2$ ), no product for the 
Table 3. List and bacterial phylogenies inferred from 16S rDNA sequences of denaturing gradient gel electrophoresis (DGGE) bands amplified by PCR from DNA extracted from scrapings of single melanized spots from individual diet-induced shell disease-affected lobsters Homarus americanus. Sample sizes show no. of individual lobsters from which samples were obtained.

Band designations correspond to Fig. 4. BLAST: basic local alignment search tool; RDP: Ribosomal Database Project

\begin{tabular}{|c|c|c|c|c|c|c|}
\hline \multirow[t]{2}{*}{ Band } & \multirow[t]{2}{*}{$\begin{array}{l}\text { Closest BLASTn match } \\
\text { (Accession no.) }\end{array}$} & \multicolumn{3}{|c|}{$\begin{array}{l}\text { Presence in DGGE of } \\
\text { PCRs using various primer sets }\end{array}$} & \multirow[t]{2}{*}{ RDP-based phylogeny } & \multirow[t]{2}{*}{$\begin{array}{l}\text { Accession } \\
\text { no. }\end{array}$} \\
\hline & & $\begin{array}{c}27 \mathrm{~F}-\mathrm{GC}+ \\
355 \mathrm{R} \\
(\mathrm{n}=10)\end{array}$ & $\begin{array}{c}\text { 341FM-GC+ } \\
907 \mathrm{R} \\
(\mathrm{n}=11)\end{array}$ & $\begin{array}{c}\text { 341FM-GC + } \\
\text { CFB721R } \\
(\mathrm{n}=11)\end{array}$ & & \\
\hline S1 & $\begin{array}{l}\text { Uncultured Rhodobacterales } \\
\text { bacterium (EF215773) }\end{array}$ & 9 & 0 & na & $\begin{array}{l}\text { Proteobacteria; Alphaproteobacteria; } \\
\text { Rhodobacterales; unclassified } \\
\text { Rhodobacteraceae sp. } 2\end{array}$ & JF297205 \\
\hline S2 & $\begin{array}{l}\text { Uncultured alpha proteobacterium } \\
\text { (AM412521) }\end{array}$ & 8 & 0 & na & $\begin{array}{l}\text { Proteobacteria; Alphaproteobacteria; } \\
\text { Rhodobacterales; unclassified } \\
\text { Rhodobacteraceae sp. } 3\end{array}$ & JF297206 \\
\hline S3 & $\begin{array}{l}\text { Rhodobacteraceae bacterium } \\
\text { strain } 197 \text { (AJ810843) }\end{array}$ & 8 & 0 & na & $\begin{array}{l}\text { Proteobacteria; Alphaproteobacteria; } \\
\text { Rhodobacterales; Rhodobacteraceae; } \\
\text { Ruegeria sp. }\end{array}$ & JF297207 \\
\hline $\mathrm{S} 4$ & $\begin{array}{l}\text { Uncultured bacterium clone } \\
\text { HH1_a4 (FN401203) }\end{array}$ & 7 & 0 & na & $\begin{array}{l}\text { Proteobacteria; Alphaproteobacteria; } \\
\text { Rhizobiales; Hyphomicrobiaceae; } \\
\text { Hyphomicrobium sp. }\end{array}$ & JF297208 \\
\hline S5 & $\begin{array}{l}\text { Uncultured alphaproteobacterium } \\
\text { G3-37 (EU005299) }\end{array}$ & 5 & 0 & na & $\begin{array}{l}\text { Proteobacteria; Alphaproteobacteria; } \\
\text { Rhodobacterales; Rhodobacteraceae; } \\
\text { Sulfitobacter sp. }\end{array}$ & JF297209 \\
\hline S6 & $\begin{array}{l}\text { Uncultured bacterium } \\
\text { Crozet_s_404 (FM213885) }\end{array}$ & 3 & 0 & na & $\begin{array}{l}\text { Proteobacteria; unclassified } \\
\text { Alphaproteobacteria sp. } 1\end{array}$ & JF297210 \\
\hline S7 & $\begin{array}{l}\text { Uncultured bacterium } \\
\text { clone A32 (GQ215673) }\end{array}$ & 6 & 0 & na & $\begin{array}{l}\text { Proteobacteria; Gammaproteobacteria; } \\
\text { Xanthomonadales; Xanthomonadaceae; } \\
\text { Lysobacter sp. } 1\end{array}$ & JF304026 \\
\hline S8 & $\begin{array}{l}\text { Uncultured Xanthomonadales } \\
\text { bacterium (GQ926873) }\end{array}$ & 5 & 0 & na & $\begin{array}{l}\text { Proteobacteria, Gammaproteobacteria; } \\
\text { Xanthomonadales; Xanthomonadaceae; } \\
\text { Lysobacter sp. } 2\end{array}$ & JF297211 \\
\hline S9 & $\begin{array}{l}\text { Propionibacterium acnes } \\
\text { ATCC6919 (AB042288) }\end{array}$ & 10 & 0 & na & $\begin{array}{l}\text { Actinobacteria; Actinobacteria; } \\
\text { Actinomycetales; Propionibacteriaceae; } \\
\text { Propionibacterium acnes }\end{array}$ & JF297212 \\
\hline
\end{tabular}

16S rDNA was amplified from any spots or lesions sampled from the 11 lobsters, including those from which a product was amplified by the 341FM+ CFB721R primer set. As this bacterium has not been cultured, a gel-purified DGGE band amplified from a lesion was used as a positive-control DNA and was effectively amplified in abundance by the specific PCR primer set. Based on these data, the unclassified Flavobacteriaceae (Band C2) DNA product amplified by the universal PCR primer set was designated as a DNA chimera and was indicated as such in silico.

\section{DISCUSSION}

Bacterial infestation of compromised lobsters has been suggested as the cause of lobster shell disease (Tlusty et al. 2007, Vogan et al. 2008). Evidence for this was shown by Tlusty et al. (2008) where lobsters fed exclusively on herring invariably became mori- bund and developed shell lesions (Tlusty et al. 2008). The same diet-based approach was used here to induce shell disease in Homarus americanus lobsters to investigate the makeup of bacterial communities that established in early-stage melanized spots and subsequent lesions.

Several bacterial types were particularly associated with DISD, with 2 species, Aquimarina 'homaria' and Kiloniella sp., found ubiquitously in both spots and lesions. To some extent, homogeneity in bacterial types that established in spots and lesions was expected due to the experimental design. For practical reasons, the cohort of 11 lobsters studied was maintained in a single tank where individuals were housed in cubicles to avoid direct contact. Based on this design, all lobsters were exposed to the same water and environmental conditions at a single location. Thus, this study represented one outbreak of DISD with a subset of 11 individuals sampled for study of their microbial communities. The same bacteria present in spots or lesions of multiple lobsters 
were due to their presence in the shared tank water, whereas differences between bacterial communities may be due to individual host factors, such as the variation in time since shell disease onset and, subsequently, sampling.

Bacteria detected in spots and lesions of lobsters with DISD were almost invariably from the Bacteroidetes or Proteobacteria phyla. Bacteria in these phyla have also been identified as common inhabitants of lesions in lobsters with epizootic shell disease collected at multiple sites in New England and Atlantic Canada over a 9 yr period (Chistoserdov et al. 2005, 2009). Propionibacterium acnes was amplified at low levels from all of the spot samples. It can potentially be a pathogen initiating the infection since it was found in 10 out of 10 samples. However, an alternative explanation is that it is a contaminant, because it was only detected in spot communities that yielded low DNA quantities. Thus, small quantities of Propionibacterium acnes cells introduced by us during sampling could have contributed DNA and become detectable by PCR. This bacterium is a normal resident of human skin (Grice \& Segre 2011), and possibly entered the system through regular water maintenance of the system. Propionibacterium acnes are slow growing, fermenting strict anaerobes, making them unlikely inhabitants of lobster surfaces.

The ubiquitous detection of Aquimarina 'homaria' in lesions of different shell disease types in wild and experimental lobsters (Chistoserdov et al. 2005, 2009), including the early-stage diet-induced spots examined here, suggests its potential role in initiating shell disease. A 16S rDNA sequence of a hypothetical unclassified Bacteroidetes bacterium belonging to Flavobacteriaceae was also detected in all samples using the Bacteroidetes-specific primer set. The universal bacterial primer set did not amplify DNA with a similar sequence, nor did specific primers for the sequence, thus indicating that it was most likely a DNA chimera (PCR artifact), which can be generated when group-specific primers are used to amplify large pools of 16S rDNA with similar sequences (Acinas et al. 2005). Indeed, the CHIMERA_CHECK program identified that its sequence was chimeric, although computer-based chimera analyses are mostly suggestive. The 16S rDNA sequences of several additional Flavobacteriaceae genera (Aquimarina sp., Krokinobacter sp., Maribacter spp., Tenacibaculum spp.) were amplified from spots and lesions, mostly with the Bacteroidetes-specific PCR primers. However, their greater prevalence in lesions suggested that these Flavobacteria may be secondary colonizers that establish as spots become lesions.
Various Proteobacteria, an unclassified Hyphomicrobiaceae sp., a Pelagibius sp., a Roseovarius sp. and the 'Candidatus Homarophilus dermatus' were also amplified from both spots and lesions of multiple lobsters but were not truly ubiquitous, suggesting their opportunistic colonization of these lobsters. In contrast, the Kiloniella sp. was a dominant constituent of almost every spot or lesion community and an unclassified Rhodobacteraceae sp. 1 was a minor constituent of all lesion communities. The 16S rDNA sequence determined for the Kiloniella sp. was $96 \%$ identical to that of Kiloniella laminariae LD81 ${ }^{\mathrm{T}}$, the only cultured Kiloniellaceae member and an aerobic chemoheterotrophic spirillum isolated from the marine brown alga Laminaria saccharina in the Baltic sea (Wiese et al. 2009). It was also 99\% identical to 'Kopriimonas byanusanensis', a novel species not described formally, and from this high sequence similarity we propose the name 'Candidatus Kopriimonas aquarianus' for this newly identified Kiloniella relative. Unlike Aquimarina 'homaria', the 'Candidatus Kopriimonas aquarianus' identified in diet-induced lesions has not been detected in lesions from free-living lobsters with ESD (Chistoserdov et al. 2009). Additional culturing of bacterial communities associated with lobster shell disease should allow enrichment for Kiloniella spp. to determine whether they infest lesions of wild lobsters with ESD and to assess their relevance to ESD more directly. The $16 \mathrm{~S}$ rDNA sequence of the Rhodobacteraceae sp. 1 matched distantly ( $90 \%$ identity) to the cultured Roseovarius pelophilus, but as it has also not been found in wild lobsters with ESD, its importance to DISD is not obvious.

DNA extracted from healthy carapace matter scraped from lobsters unaffected by DISD did not amplify by PCR using universal bacterial 16S rDNA primers. Thus few bacteria colonized the healthy cuticle of juvenile lobsters in our system, as the exact same method was used on healthy carapaces of wild adult lobsters and bacterial communities were readily amplifiable (Chistoserdov et al. 2009). However, Aquimarina 'homaria' was amplified in low abundance from 2 of 6 lobsters using specific PCR primers, indicating that its abundance might have been below the detection threshold for the universal PCR primers. Whether this is normal and due possibly to juvenile lobsters molting more frequently than adults or to their maintenance in an artificial aquarium environment is not known. However, consistent with this, DNA yields from melanized spot scrapings were much lower than those from lesion scrapings, indicating that bacterial loads increase in lesions. 
The analysis of bacterial communities between spots and lesions from the 11 lobsters with DISD showed a more diverse assemblage in spots than in lesions, suggesting that the community constituents stabilize over time or that some constituents overgrow less abundant members. Only 2 bacteria, Aquimarina 'homaria' and 'Candidatus Kopriimonas aquarianus', were found to persist universally as spots progressed to lesions (Table 1). Other than these bacteria, the bacterial communities are apparently dynamic in composition, with some bacteria having colonized spots being lost and others establishing as lesions develop and progress in severity.

While these observations on the bacterial community give clues to future research directions to identify community dynamics over shorter time scales, which bacteria escalate in communities as spots transition to lesions and, ultimately, which bacteria contribute to disease, the caveat remains that the data were gathered from a small cohort $(n=11)$ of lobsters cohabitated and exposed to exactly the same feed and water conditions. Thus, in our single experimental system, the source of the bacteria identified in association with DISD-induced shell pathology is likely either the herring used to prepare the diet or the bacterial community in the aquarium water taken in from Boston harbor; as such, extrapolations to bacterial communities of shell disease in wild lobsters are not easily made. It is notable however, that some of the same bacteria detected in DISD lesions here are also commonly detected in wild outbreaks of shell disease (Chistoserdov et al. 2005, 2009) and wild lobsters are known to consume high levels of fish from baited traps (Bethoney et al. 2011).

It is apparent from this and others studies that lobster shell disease lesions comprise complex communities of microbes possibly acting in concert to induce pathology (Chistoserdov et al. 2002, 2005, Smolowitz et al. 2005, Quinn et al. 2009). The experimental system in which the lobsters were maintained used seawater that was circulated through a biofilter at a rate of $\sim 15 \%$ water exchange per day and therefore does not contain bacterial diversity likely to exist in natural environments. While the data on DISD cannot be used directly to infer what causes ESD in wild lobsters, the ubiquitous detection of Aquimarina 'homaria' in DISD lesions adds further weight to it being involved in shell lesion development in lobsters irrespective of how it is induced (Chistoserdov et al. 2002, 2005, Smolowitz et al. 2005). The common detection of other bacteria in lesions, including 'Candidatus Kopriimonas aquarianus' and various members of the Rhodobacteraceae, Rhodospirillaceae, and Hyphomicrobiaceae, also implicated these as possible agents contributing to DISD, and it will be interesting to determine whether these bacteria also occur commonly in lesions of wild lobsters affected by ESD. It will be interesting to compare the results from this study to those with more controlled microbial communities, such as sterile sea water or tanks inoculated with different bacterial strains to monitor the complex dynamics of lesion communities as shell disease progresses.

Acknowledgements. This work was supported by NOAA Grant NA06NMF4720100 to the University of Rhode Island Fisheries Center from the National Marine Fisheries Service. The views expressed herein are those of the authors and do not necessarily reflect the views of NOAA or any of its sub-agencies. The US Government is authorized to produce and distribute reprints for government purposes, notwithstanding any copyright notation that may appear hereon.

\section{LITERATURE CITED}

Acinas SG, Sarma-Rupavtarm R, Klepac-Ceraj V, Polz MF (2005) PCR-induced sequence artifacts and bias: insights from comparison of two 16S rRNA clone libraries constructed from the same sample. Appl Environ Microbiol 71:8966-8969

Altschul SF, Madden TL, Schäffer AA, Zhang J, Zhang Z, Miller W, Lipman DJ (1997) Gapped BLAST and PSIBLAST: a new generation of protein database search programs. Nucleic Acids Res 25:3389-3402

Bethoney ND, Stokesbury KDE, Stevens BG, Altabet MA (2011) Bait and the susceptibility of American lobsters Homarus americanus to epizootic shell disease. Dis Aquat Org 95:1-8

Castro KM, Angell TE (2000) Prevalence and progression of shell disease in American lobster, Homarus americanus, from Rhode Island waters and the offshore canyons. J Shellfish Res 19:691-700

Castro KM, Factor JR, Angell TE, Landers DF (2006) The conceptual approach to lobster shell disease revisited. J Crustac Biol 26:646-660

Chistoserdov AY, Mirasol F, Smolowitz RM (2002) Characterization of microbial assemblages involved in the development of shell disease in the American lobster, Homarus americanus. J Shellfish Res 21:410

Chistoserdov AY, Smolowitz RM, Mirasol F, Hsu AC (2005) Culture-dependent characterization of the microbial community associated with epizootic shell disease lesions in American lobster, Homarus americanus. J Shellfish Res 24:741-747

Chistoserdov AY, Quinn RA, Gubbala SL, Smolowitz RM (2009) Various forms and stages of shell disease in the American lobster share a common bacterial pathogen in their lesions. J Shellfish Res 28:689

Cobb JS, Castro KM (2006) Shell disease in lobsters: a synthesis. Rhode Island Sea Grant, Narragansett, RI

Getchell RG (1989) Bacterial shell disease in crustaceans: a review. J Shellfish Res 8:1-6

Grice EA, Segre JA (2011) The skin microbiome. Nat Rev Microbiol 9:244-253 
Hong SH, Bunge J, Leslin C, Jeon S, Epstein SS (2009) Polymerase chain reaction primers miss half of rRNA microbial diversity. ISME J 3:1365-1373

Howard DW, Lewis EJ, Keller BJ, Smith CS (2004) Histological techniques for marine bivalve mollusks and crustaceans. NOAA Tech Memo NOS-NCCOS, Vol 5. NOAA Center for Coastal Environmental Health and Biomolecular Research, Cooperative Oxford Laboratory, Oxford, MD

> Hsu AC, Smolowitz RM (2003) Scanning electron microscopy investigation of epizootic lobster shell disease in Homarus americanus. Biol Bull (Woods Hole) 205: 228-230

Jaccard P (1908) Nouvelles recherches sur la distribution florale. Bull Soc Vaud Sci Nat 44:223-270

Malloy SC (1978) Bacteria induced shell disease of lobsters (Homarus americanus). J Wildl Dis 14:2-10

Manly BFJ (1991) Randomization and Monte Carlo methods in biology, 1st edn. Chapman \& Hall, London

> Muyzer G (1999) DGGE/TGGE a method for identifying genes from natural ecosystems. Curr Opin Microbiol 2: 317-322

Muyzer G, de Waal EC, Uitterlinden AG (1993) Profiling of complex microbial populations by denaturing gradient gel electrophoresis analysis of polymerase chain reaction-amplified genes coding for 16S rRNA. Appl Environ Microbiol 59:695-700

Quinn RA, Smolowitz RM, Chistoserdov AY (2009) Eukaryotic communities in epizootic shell disease lesions of the American lobster (Homarus americanus H. Milne Edwards). J Shellfish Res 28:913-922

Real R, Vargas JM (1996) The probabilistic basis of Jaccard's index of similarity. Syst Biol 45:380-385

SAS (Statistical Analysis Systems) (2008) SAS/STAT 9.2

Editorial responsibility: Jeff Cowley,

Brisbane, Queensland, Australia user's guide. SAS Institute, Cary, NC

Smolowitz RM, Bullis RA, Abt DA (1992) Pathologic cuticular changes of winter impoundment shell disease preceding and during intermolt in the American lobster, Homarus americanus. Biol Bull (Woods Hole) 183:99-112

Smolowitz RM, Hsu AC, Summers E, Chistoserdov AY (2002) Lesions associated with recent epizootic shell disease in Homarus americanus on the northeast coast. J Shellfish Res 21:412

Smolowitz RM, Chistoserdov AY, Hsu AC (2005) A description of the pathology of epizootic shell disease in the American lobster, Homarus americanus, H. Milne Edwards 1837. J Shellfish Res 24:749-756

Stewart JE (1980) Diseases. In: Cobb JS, Phillips BF (eds) Physiology and behavior. The biology and management of lobsters, Vol 1. Academic Press, New York, NY, p 301-344

Tlusty MF, Smolowitz RM, Halvorson HO, DeVito SE (2007) Host susceptibility hypothesis for shell disease in American lobsters. J Aquat Anim Health 19:215-225

Tlusty MF, Myers A, Metzler A (2008) Short- and long-term dietary effects on disease and mortality in American lobster Homarus americanus. Dis Aquat Org 78:249-253

Vogan CL, Powell A, Rowley AF (2008) Shell disease in crustaceans-just chitin recycling gone wrong? Environ Microbiol 10:826-835

> Wiese J, Thiel V, Gärtner A, Schmaljohann R, Imhoff JF (2009) Kiloniella laminariae gen. nov., sp. nov., an alphaproteobacterium from the marine macroalga Laminaria saccharina. Int J Syst Evol Microbiol 59:350-356

> Weller R, Glöckner FO, Amann R (2000) 16S rRNA-targeted oligonucleotide probes for the in situ detection of members of the phylum Cytophaga-FlavobacteriumBacteroides. Syst Appl Microbiol 23:107-114

Submitted: March 31, 2011; Accepted:January 17, 2012 Proofs received from author(s): April 13, 2012 